\title{
Entre Cádiz y México ante la independencia de América. Revisión documental y lingüística*
}

\author{
Juan Antonio Frago ${ }^{* *}$ \\ Universidad de Zaragoza, España
}

\begin{abstract}
Resumen
No ha recibido la atención que sin duda merece el relevante papel jugado por Cádiz en la relación del español peninsular con el americano, a pesar de haber sido especialmente importante desde que esta ciudad tuvo el monopolio del tráfico indiano, todavía muy importante cuando otros puertos pudieron participar en el comercio ultramarino. Se propone aquí un avance documental sobre este particular contacto entre las dos orillas del Atlántico hispánico, teniendo en cuenta cartas intercambiadas por agentes mercantiles gaditanos, y se sacan las consecuencias lingüísticas que su análisis permite, con vistas a una mejor descripción del español americano preindependiente.
\end{abstract}

Palabras clave: el texto epistolar, contactos interdialectales, el español americano preindependiente.

* Del proyecto de investigación FFI2011-24806, Ministerio de Economía y Competitividad.

** Para correspondencia, dirigirse a: Juan Antonio Frago Gracia (jafrago@unizar.es), Departamento de Lingüística General e Hispánica, Facultad de Filosofía y Letras, Universidad de Zaragoza, Pedro Cerbuna 12, 50009 Zaragoza, España. 


\title{
Between Cadiz and Mexico in the light of American INDEPENDENCE. Documental and Linguistic REVIEW
}

\begin{abstract}
The important role played by Cadiz respecting the relationship existing between the Spanish spoken in Europe and America has not received the attention it certainly deserves, in spite of the fact that this city had the Indian traffic monopoly, even very important when other ports could participate in overseas trade. We propose here a documented advance on this contact between the two sides of the Hispanic Atlantic, considering commercial letters exchanged by Cadiz agents, and the linguistic consequences that their analysis enables, looking forward to a better pre-independence American Spanish description.
\end{abstract}

Key words: epistolary text, interdialectal contacts, pre-independence American Spanish.

Recibido: 01/02/13 Aceptado: 17/04/13

\section{NOTAS PRELIMINARES}

Se presentan y estudian en este trabajo tres cartas de Rafael Orozco, escrita la primera a punto de partir de Cádiz hacia América en 1784, redactadas las otras en Nueva España el año siguiente, meses antes de que nuestro personaje emprendiera viaje de retorno al puerto gaditano. Era destinatario de las misivas Miguel de Iribarren, acaudalado hombre de negocios en el Cádiz de la segunda mital del siglo XVIII, que, originario de Pamplona, donde había nacido el año 1731, estaba afincado en esta ciudad andaluza desde 1771 (Martínez del Cerro González 2006: 401).

El emprendedor navarro mantuvo importantes relaciones comerciales con plazas europeas e indianas, a esta actividad económica se refieren los textos epistolares de Orozco, y de hecho Iribarren junto a su hermano Ramón se había asentado en Cádiz tras una larga estancia en tierras novohispanas, donde conservaría intereses comerciales y estrechos contactos personales. Muestra de ello, entre tantas noticias que al respecto se conocen, es la carta que el 30 de noviembre de 1778 dirige Domingo Elizondo desde México a María Morán, residente en Medina de Rioseco, en la cual puede 
leerse: "Ygual remito por este correo a mi corresponsal el Sr. Dn. Miguel de Yribarren, del comercio de Cádiz, para que entregue a los sujetos que contiene el mencionado documento a excepción de los doscientos y cincuenta pesos que están señalados al difunto marido de vuestra merced"1.

En cuanto a Rafael Orozco, era capitán de navío de la Real Armada, con residencias duraderas en la Corte como apoderado de Iribarren, con quien colaboró en sus empresas, pues por ejemplo dos años después de fechar su tercera carta estaba vendiendo productos de herrería para el navarro en América, aunque igualmente llevó negocios propios, de importación de azúcar indiano, según refiere la investigadora citada (2006: 407, 430, $437)^{2}$. Orozco formaba parte de una red de solidaridad social y de paisanaje nucleada por Miguel de Iribarren, semejante a otras que articularon el quehacer de los españoles con importantes intereses económicos en América. Sobre su naturaleza regional, el análisis textual descubre indicios de que probablemente fuera andaluza.

Aparte de las tres cartas en cuestión, manejaré testimonios de otros documentos que ponen de relieve la estrecha relación de Cádiz con América en la época que nos ocupa, décadas precedentes a la independencia de las colonias americanas continentales, y por ende las afinidades lingüísticas entre este emporio de negocios indianos y de su entorno regional con el mundo hispanoamericano. Bien es verdad que no solo los hombres de comercio fueron protagonistas de dicho contacto, sino toda una ciudad que le había arrebatado a Sevilla su condición de "puerta indiana", en expresión de Lope de Vega, y que, llegada la invasión de los ejércitos napoleónicos, se convertiría en único nexo de unión entre la Península y Ultramar.

De hecho la urbe gaditana sería abigarrado y cosmopolita centro de presencias americanas -clérigos y mercaderes, representantes políticos de las colonias, pleitistas y militares-. De allí el año 1811 saldría hacia Inglaterra el entonces teniente coronel del ejército español José de San Martín, camino de ser el libertador del Río de la Plata y apoyo decisivo para la independencia de Chile y Perú (Lynch 2009: 48-55), y en La Carraca de San Fernando moriría prisionero el precursor venezolano Francisco de Miranda. Los archivos de la ciudad y de su provincia abundan en noticias de todo tipo, por supuesto incluidas las de interés lingüístico, sobre la América preindependiente y

\footnotetext{
Archivo de la Real Chancillería de Valladolid (ARChV), Pleitos Civiles, Pérez Alonso, Fenecidos, caja 3343-2.

2 En la misma caja y expediente archivístico de las tres cartas luego aducidas (v. notas 6,8 ) hay otras de Orozco escritas en Madrid y El Escorial, en las que da cuenta a Iribarren de la marcha de su apoderamiento.
} 
sobre los mismos años de las guerras emancipadoras, acontecimientos que encontraron amplio eco en periódicos, opúsculos y otras publicaciones de la Isla de León, a donde fueron enviados no pocos reos del bando insurgente.

Es así fácil, por ejemplo, abrir al azar un legajo notarial y encontrarse con un documento como el de la otorgación de poderes del "Dr. Dn. Marcos Dongo, natural del Reyno de Perú, preso en la Real Cárcel, a procuradores", en el que, entre otras cosas, se lee: "en la ciudad de Cádiz, en veinte y tres días del mes de julio de mil ochocientos diez, ante mí, el escribano público de número de esta plaza, estando en la Real Cársel, pareció el Dr. Dn. Marcos Dongo, natural y vecino del Reyno del Perú preso en ella..." 3 A semejanza de los textos americanos de la época, no resultan insólitas en este grafías seseo-ceceosas como cársel y priciones, o ecepciones en carta particular inserta del mismo $1810^{4}$, ni el empleo de pareció con el sentido de 'compareció' (236v), o el del adjetivo indefinido cualquiera concordado en plural con sustantivo en singular, "y en adelante tuviere contra qualesquiera persona", uso que registra otro poder notarial del mismo legajo: "que me ayuden y defiendan en todos mis pleytos, causas y negocios de qualesquier naturaleza" (194r) $)^{5}$.

3 Archivo Histórico Provincial de Cádiz (AHPC), Pedro de Montes, 2618, fs. 132r, 264r-v, 265r, para los datos grafémicos aquí citados.

4 Sin embargo, para el particular caso de Cádiz estos lapsus cálami únicamente aseguran la indistinción articulatoria de $s$ y de $c-z$, pero no si quien los comete seseaba o, por el contrario, ceceaba. Distinto sería el caso del texto con registro exclusivo de $c$ y $z$ por $s$, como son los consultados de Orozco, circunstancia que permitiría apuntar la hipótesis de un ceceo fonético.

Todavía el 14 de marzo de 1820 en acta del Cabildo malagueño se lee: "teniendo presente qualesquiera que en este particular hubiese ocurrido en la noche del 11 del corriente": Archivo Municipal de Málaga, Actas de Cabildo, 212-I, f. 99r. En el español escrito de los vascongados es frecuente su registro, así en carta dada en Pasajes el 14 de marzo de 1801 por Joaquín de Barandiarán, poco antes llegado de Lima tras muchos años de permanencia en tierras peruanas: "lo que me será muy fácil satisfacer a qualesquiera con documentos jurídicos": ARChV, Pleitos Civiles, Zarandona y Walls, Olvidados, caja 3104-4. En carta de Juan Felipe de Orueta a Joaquín de la Concha, escribano de la villa de Bilbao, fechada en 1755: "en qualesquiera parte puede vuestra merced reconozerlo": ARChV, Sala de Vizcaya, caja 1073-3; y en otra dada dos años antes en el mismo Bilbao: "con otro qualesquiera que pretenda tener derecho": ibíd., caja 2486-5. 


\section{DEL EPISTOLARIO DE RAFAEL OROZCO}

\subsection{PRIMERA CARTA ${ }^{6}$}

Mi más querido amigo: la salida mañana solo estriba en que el viento sea en popa o aún largo, para que pueda executarlo La España, y nosotros le seguiremos, embarcándose el Conde a las 7 según ha quedado conmigo esta tarde, lo que serbirá a vuestra merced de noticia para los asumptos pendientes, a cuya hora iré yo a su casa para acompañarle.

Incluyo los tres papeles firmados, según vuestra merced me dijo.

Si tubiere un instante mañana, lo emplearé en darle a vuestra merced un abrazo, pero si no, sepa que en mí tiene y tendrá un finíssimo amigo, que le vibe agradecidíssimo y decea únicamente que se le proporcionen muchas occaciones de servirle, como lo experimentará siempre que me dé la satisfacción de mandarme en quanto guste. Espero que assí lo executará vuestra merced, para que pueda en algo satisfacer mi deceo de obsequiarle, quedando siempre de vuestra merced su fino amigo que su mano besa.

Rafael Orozco (rubricado)

De 28 octubre 84

Sr. Dn. Miguel de Yrribarren

\subsubsection{Comentario}

Carta autógrafa, con igual letra en texto y firma, sin tildes acentuales y sin más puntuación ortográfica que el punto final de sus tres párrafos, más otro punto con valor de coma al final de la misiva: "para que pueda en algo satisfacer mi deceo de obsequiarle (.) quedando siempre de vuestra merced su fino amigo", y los dos puntos por coma en una ocasión: "lo que serbirá a vuestra merced de noticia para los asumptos pendientes (:) a cuya hora iré yo a su casa”, y como punto y seguido al término de la carta: “... me dé la satisfacción de mandarme en quanto guste (:) Espero que assí lo executará vuestra merced". Emplea las abreviaturas dieciocho veces en tan corto texto (en amigo, para, que, siempre, vuestra merced, etc.), y en el formulario Q

\footnotetext{
6 AHPC, Fundación Luis Goytisolo, Familia Iribarren, caja 63, expediente 1. De todas las cartas dirigidas a Miguel de Iribarren que he leído solo en las de Orozco su apellido se escribe Yrribarren.
} 
S M B 'que su mano besa'. El uso de las mayúsculas es reiteradamente arbitrario, con bastantes registros de $b$ por $v$, y con una doble ese en los superlativos (agradecidíssimo, finíssimo) y en assí, arcaísmo ortográfico que de manera más o menos ocasional se encontrará hasta entrado el siglo XIX, igual que la jota sin punto, pero con el trazo de la letra sobresaliendo de la caja de escritura.

El ceceo gráfico aparece en decea, deceo y occaciones, lo que apuntaría a un autor andaluz, tal vez gaditano ceceoso, hipótesis que en principio no casaría con el leísmo de persona de esta carta (acompañarle, le seguiremos, obsequiarle, serbirle), con distinción etimológica si el complemento directo es de cosa: "si tubiere un instante mañana, lo emplearé..." Esta constatación gramatical no parecería corresponder a un natural de Andalucía y sí a un hablante norteño (v. n. 7). Los mismos rasgos lingüísticos se verifican en otras piezas del epistolario de Orozco, verbigracia el leísmo en carta que escribe a Miguel de Iribarren en Madrid el 22 de diciembre de 1786: "Solano llegó bueno y oi ha besado la mano a las Personas Reales, quienes le han honrrado mucho", y el desliz grafémico en la posdata de otra que le envía el 29 del mismo mes: "luego que reciba vuestra merced esta, pase a ver a mi madre y que le manifieste mi carta, que le digo le enseñe, pues nececito su dictamen de vuestra merced"?.

\subsection{SEgunda CARTA ${ }^{8}$}

Veracruz, a 2 de noviembre de 1785.

Querido amigo: E1 28 del próximo pasado octubre dí fondo en este puerto a las 8 de la noche con toda felicidad, pues ha sido cuidadosilla la nabegación por la crítica estación y hemos sufrido un fuerte norte al tercer día de la salida de La Havana, el que aguantamos 30 horas en la sonda, y, temeroso de que a la entrada de Veracruz me diese otro en tan peligroso sitio, emboqué a el

\footnotetext{
Con la misma referencia archivística de la nota 6. Respecto de la cuestión lingüística, son muchos los leísmos que registran textos de andaluces de finales del siglo XVIII y principios del XIX, que más que corresponder al habla de su región podrían ser meros reflejos de la influencia en la lengua escrita de modelos tenidos por más prestigiosos, lo cual asimismo se verifica en América por aquellos años (v. n. 33). Arriba indica Orozco que su madre residía en Cádiz y la construcción $y a+\mathrm{S}+\mathrm{V}$ de la que luego se tratará en principio inclina a adscribirlo a la modalidad andaluza.

8 Esta segunda carta y la tercera tienen la signatura de la nota 6 , expediente 2 de la caja 63.
} 
puerto de noche. Balisando los bajos con faroles, ha querido Dios que me saliera bien, pues acavado de amarrarme a el castillo, entró el norte.

El estado de mis dependiencias, poco más o menos como el general de todo este Reyno, cuias repetidas lástimas tiene vuestra merced ya entendidas y oirá su repetición incesante, mientras que ese comercio de por sí [no] ponga los límites que tan precisos son a sus remesas, y de no hacerlo perecerán todos sus caudales.

Acaban de benderse 16.000 barriles de vino a 10 pesos y 2 rreales. Los lienzos el regular prometter por ellos es 25 por $\%$ menos del principal de España. El aguardiente 20-22 pesos, y por último es rara la escriptura que se paga.

Nuestro Piedras, no obstante su sin segunda pachorra, está asombrado, pues en quanto emplea, pierde. Si [a] un hombre de su conocimiento y práctica en el Reyno de 40 años le subcede esto, ¿al que benga de ay, qué le subcederá?

En fin, me daré por contento si cobro las escriptturas.

Yo paso a México inmediatamente, así para despedirme de mi querido Virrey como para ber el estado de algunos efectos que hice subir.

A el nuebo Governador de La Havana discurro conduciré en esta fragatta, que se halla en Jalapa recuperando la salud de su mujer, que se hallaba mui quebrantada de resultas de un mal parto.

Vuestra merced bea si tengo alguna cosa en que serbirle, pues en un todo desea complacerle su más afecto amigo y servidor, que de corazón lo quiere y su mano besa.

Rafael Orozco (rubricado)

Sr. Dn. Miguel de Yrribarren

\subsubsection{Comentario}

Esta carta y la siguiente llevan la firma autógrafa de Rafael Orozco, pero sus textos son de otra letra, la misma en ambos casos, de mejor caligrafía y de ortografía más moderna, cuya factura probablemente se debe a un amanuense al servicio de la compañía comercial de Iribarren en su dependencia novohispana, exceptuado el párrafo final de la tercera misiva. El uso de las mayúsculas, aun presentando algunas vacilaciones, está más regularizado que en Orozco, lo mismo que la puntuación, con reiteración de la coma, casi siempre con su actual valor, y con el empleo de los signos de interrogación. Este escribano emplea la tilde en la conjunción disyuntiva (o), y con carácter fonético en bér del sexto párrafo; en ocasiones duplica 
la $t$ (efecttos, escriptturas, nortte, etc.), según tendencia escrituraria muy extendida en el siglo XVIII.

La regularidad ortográfica sin embargo no es total, pues aunque la mediopalatal $/ \mathrm{y} /$ tiene la grafía $y$, también una vez se escribe con $i$ (cuias), y son corrientes en este texto los errores de $b$ por $v$ (bea, benderse, nabegación, etc.), con el lapsus contrario solo en el caso de Havana, y frente a la modernidad de que en términos comparativos he hablado, en esta carta se verifica la muy tradicional costumbre de adornar la ye con rayita oblicua o curva, en la copulativa $y$ así como en el adverbio ay 'ahí' del cuarto párrafo.

Antes de abordar el análisis más propiamente lingüístico es preciso recordar que en esta carta de Orozco únicamente es autógrafa su firma, algo nada raro en esta clase de correspondencia, pues los grandes comerciantes peninsulares contaban con representantes y empleados en América, tanto españoles como criollos. El amanuense de Orozco sin duda copió sus cartas al dictado, pues si no mal se entendería la falta del adverbio no que mi transcripción restituye entre corchetes, en el pasaje "mientras que ese comercio de por sí [no] ponga los límites...", seguramente descuido del copista, igual que en aquel construido sin la preposición $a$ ("si [a] un hombre de su conocimiento... le subcede esto..."), aparte de lo que al respecto indican la datación y las líneas de puño y letra de Orozco en la tercera carta.

El estilo también corrobora un procedimiento de dictado, pues es evidente que a Orozco y no al copista se deben su coloquialismo y la intención irónica que transmite esta observación: "Nuestro Piedras, no obstante su sin segunda pachorra, está asombrado, pues en quanto emplea, pierde". Pero Piedras corresponde al apellido en forma singular de un hombre de negocios establecido en Nueva España y bien conocido tanto de Orozco como de su amanuense, por lo que la $-s$ superflua que su apellido presenta en esta misiva más que referencia dialectal, indicación de aspiración o pérdida de la /-s/ implosiva, es muestra del juego irónico que se gasta a costa de este personaje (v. n. 11). En el gerundio balisando se aprecia un único ejemplo de seseo, como ocurre con losa 'loza' en la siguiente carta. Hay más leísmo de persona que distinción etimológica en el breve párrafo último de la misiva: complacerle, serbirle/lo quiere. De los marinerismos léxicos me ocuparé en el comentario a la siguiente carta ${ }^{9}$.

$9 \quad$ En dependiencias tal vez más que vulgarismo hay descuido ocasional por cruce con dependiente. 


\subsection{TERCERA CARTA}

México, 2 de noviembre de 1785.

Querido amigo: Por la fragata La Diligencia he recivido la de vuestra merced, en que se refería a la que tenía escriptta por el correo, pero como el de primeros de septtiembre no ha llegado, y lo mismo el de primero (sic) de octtubre, no he recivido más noticia que la dicha.

Yo llegué a esta capital el 1 de noviembre, fui recivido de nuestro amado Virrey y Virreyna con tanto exceso de cariño que se corre mi modestia de conttar al extremo que han llegado sus attenciones, pues, aloxados en su palacio, logró (sic) el gusto de comer con él diariamente; me ha dado un gran coche, me ha puesto mi balcón de loros, y, en fin, no queda expecie de distinción que su vondad no me dispense, lo que agraba en mí la mucha pena que tengo de dejarlo.

Mi salida de Veracruz debe ser el 6 de henero próximo, conduciendo a la señora Virreyna viuda, y setecientos mil pesos del Rey, habiéndose acelerado mi viage, que debía ser por abril, por la precisión de que llegue con la promptitud posible este caudal.

Aunque están en ser (sic) todavía todos los géneros que contenían los baúles que vuestra merced dispuso, toda la ancheta que vino en la Ynfanta Doña María Josefa, toda la losa y vidrios, todos los caserillos, la mitad de las cregüelas y aceyte, que ya vuestra merced be que importa lo dicho los dos tercios de todo quanto tragimos, procuraré que baya en la fragata la mitad del importte de las escriptturas quando menos, y el resto en el rexistro que llebe el Astuto o el San Phelipe, que debe salir de aquí a principios de abril, lo que puede vuestra merced desde luego asegurar a los interesados para su govierno.

Ya vuestra merced y todos saben en esa el infelicíssimo y deplorable estado en que está toda esta parte de América, que aquí en el día no solo no se gana, sino que no hay quien quiera los géneros ni aún por el principal de España, y a el fiado; ya vuestra merced bee si puede llegar a estar peor el asumptto. Todo lo causa el que aún apenas ha llegado un navío, quando tocan (sic) otro, y este trae la noticia o de muchas otras licencias o de barios navios que estaban para salir. No explayándome más sobre este asumptto, pues sé que vuestra merced tiene bien individualizadas estas y otras fatales noticias, lo que sí le aseguro es que pueden dar gracias a Dios los que nos han dado el dinero de que haya caído en mis manos, pues Piedras y Goya están asombrados de ver las eficacísimas diligencias que he hecho para bender en medio de tantos cuidados como puede vuestra merced considerar que me habrán cercado, pues barios géneros ha habido que han estado en La Havana, han hido a Veracruz y han buelto a benderse a La Havana. Se 
pagarán las escriptturas con la corta retardación que vuestra merce be, que creo que si no son las únicas, pocas ha de haber que las igualen. De aquí podrá vuestra merced inferir el poco o ningún fruto que dejará el viage en la parte lucrosa, pero sí, a Dios gracias, en honor y estimación, que es lo principal, pues todos estos señores se han dado por satisfechos y he logrado el gusto de hacer buenos servicios a su merced y emplear la amistad en nuestro Conde en hacer mucho bien, que es la principal y más segura ganancia.

En el correo que saldrá a principios de enero remitiré los conocimientos, pues en este no es posible.

Vuestra merced crea que me he visto apuradíssimo para esta remición de dinero, pues no hai absolutamente quien compre, y ya sabe vuestra merced lo que es ir a rogar con los géneros. En fín, hemos pedido prestado un poco de dinero, pues si no ni el principal de España ni los dos tercios hubiéramos sacado. Páselo vuestra merced bien y mande a su afectísimo amigo que su mano besa.

Rafael Orozco (rubricado)

Sr. Dn. Miguel de Yrribarren

\subsubsection{Comentario}

Hay dos letras bien diferentes en esta carta, una la de quien seguramente dependió el error de fecharla igual que la anterior, así como el descuido de poner logró por logré y la discordancia gramatical de tocan con sujeto singular (quinto párrafo). Y luego está la parte autógrafa de Orozco en el último párrafo, en su firma y en el nombre del destinatario, añadido que seguramente se debe a su insistencia en la justificación de un negocio poco rentable para Iribarren.

Siendo un mismo escribano el redactor de estas dos misivas, no solo coincide en ellas la caligrafía, sino los signos de puntuación, así como el de la tilde sobre la conjunción $o$, sistemático en esta y ocasional sobre la preposición $a$, además de la tilde fonética que se halla en las siguientes voces de los párrafos indicados entre paréntesis llegué $\left(1^{\circ}\right)$, caúdal con evidente dislocación $\left(3^{\circ}\right)$, bé, sér $\left(4^{\circ}\right)$, beé, bé, és, puéde, sé $\left(5^{\circ}\right)$. En el superlativo emplea tanto la doble ese (infelicíssimo) como la simple (eficacísimas). La parte autógrafa de Orozco reitera su conocida ortografía, con el uso de los dos puntos como punto y seguido: “...ya sabe vuestra merced lo que es ir a rogar con los géneros (:) Páselo vuestra merced bien...”, la anárquica distribución de las mayúsculas y la -ss- en apuradíssimo. También resulta arcaizante por la $i$ latina final de hai. 
Por su interés lingüístico anoto el refuerzo con /g/ del diptongo /wé/, en cregüelas 'crehuelas', a finales del siglo XVIII ya de una connotación popular que contrasta con el hipercorrecto expecie, y en el texto epistolar destaca la forma bee 've', como variante de los dos registros de be y el de ber, caso que para la época supone un notable arcaísmo y del que he recogido varios ejemplos en manuscrito canario de 1721 (1999: 278). Asimismo se verifica la secuencia de preposición $a$ y artículo el sin aglutinar ( $a$ el fiado), frente a la contracción del (del Rey, del importe), semejantemente a lo que sucede en la carta anterior: a el puerto, a el castillo, a el nuevo governador / al que benga y del principal.

Mayor importancia en cuanto a la posibilidad de tipificación dialectal que ofrece es la consideración grafémica referente a la /-s/ implosiva, y a este respecto recordaré que en la anterior carta el apellido Piedra presentaba una ese final susceptible de responder a juego burlesco del autor, supuesto que en esta tercera misiva ("pues Piedras y Goya están asombrados...") no tiene apoyo contextual, si no es por repetición de un cliché onomástico. Pero está la variación "el de primeros" y "el de primero" del párrafo inicial, sobre lo cual debe recordarse que la navegación atlántica a vela no permitía un preciso día de arribada, así como la discutible concordancia en "pues, aloxados en su palacio, logró..." Sin embargo no se puede afirmar categóricamente la referencia al fenómeno de aspiración o pérdida de dicha consonante, que en todo caso seguramente correspondería al copista, igual que el seseo manifestado por la grafía losa 'loza', rasgo fónico de tipo meridional al que se suma la grafía remición de puño y letra de Orozco. Como referencia diatópica se halla también el esquema morfosintáctico ya $+\mathrm{S}+\mathrm{V}$ en $\mathrm{Ya}$ vuestra merced be que importa lo dicho, Ya vuestra merced y todos saben... y Ya vuestra merced bee..., modismo perfectamente compatible con la naturaleza andaluza del autor, así como el empleo del átono lo masculino como complemento directo ("la mucha pena que tengo de dejarlo"). Un sainete de 1781, de probable autor andaluz, registra la construcción Ya la cena está aguardando, y otro de la época, sin duda del mismo tipo regional, frente a un Tú ya conoces su genio trae los ejemplos de Ya tú ves que no conviene, Ya yo veo que cumplís, Ya yo llevo mi dinero (Ripodas Ardanaz y Lapuista 1986: 142, 256, 259, 261).

Rafael Orozco asegura la plena familiaridad de quienes frecuentaban la Carrera de Indias con el indigenismo loro ("me ha puesto mi balcón de loros"), y desde luego con la terminología marinera, en la segunda carta aguantar la sonda, amarrar, balizar los bajos, dar fondo, embocar el puerto, entrar el norte, sufrir un fuerte norte, en él nada extraño siendo como era capitán de navío. De esta circunstancia durante mucho tiempo mantenida derivó la creación de numerosos marinerismos de tierra adentro, de la 
importancia para el español americano que recientemente he puesto de relieve (2010: 59-94), y que ya tienen algún anticipo en las misivas transcritas. El fuerte norte del que Orozco en la segunda habla es el 'viento frío y fuerte que sopla del norte', según el diccionario de la Asociación de Academias de la Lengua Española define a grandes rasgos semánticos y con descripción diatópica que deberá completarse (2010: 1507), con más concreta acepción en Santamaría, 'viento que sopla del norte, por lo común en los meses de octubre a diciembre, a veces hasta enero o febrero, en la zona tropical' (1978: 763), definición que concuerda con la que a nortes da O'Scanlan: 'temporales de este rumbo en la América septentrional y más señaladamente en el Seno mejicano', advirtiendo que "en el verano, cuando este viento es suave, le llaman viento a la cabeza", y concretando más adelante que así "llaman en Veracruz al mismo norte, cuando reina con suavidad en los meses de verano, y particularmente en agosto y septiembre" $(1831 / 1974: 384,554)^{10}$. Con sentido mercantil se halla ancheta en la tercera, "toda la ancheta que vino en la Ynfanta Doña María Josefa", término del comercio indiano, que en el español ultramarino se desarrolló polisémicamente y en derivados morfológicos; se encuentra también en la misiva que Diego Barreda remite de México (1 de septiembre de 1783) a Cádiz para don Pedro Daza y Guzmán: "no dejes de informar a mi hermano del grande perjuicio que me han echo en auisarme que venía la ancheta, y no hauerse verificado"

Respecto del marco extralingüístico de esta comunicación epistolar, la segunda carta menciona a un indiano apellidado Piedra, a quien Orozco atribuía "conocimiento y práctica en el Reyno de 40 años", y que en esta de nuevo es mencionado junto a un Goya, don Manuel Ramón de Goya, guipuzcoano, que en su condición de albacea en México de Juan Ignacio de Arranechea escribe a un apoderado del difunto en Oyárzun, y que también

10 No parece, en efecto, que sea uno mismo el norte que sopla en zona tropical de la América septentrional y central que el de Uruguay, una de las localizaciones de esta voz en el citado diccionario de la Asociación de Academias de la Lengua Española, ni es creíble que el viento así llamado se quede en Uruguay sin pasar a la vecina Argentina.

11 AHPC, Fundación Luis Goytisolo, Familia Iribarren, caja 53, expediente 10. Sobre el, a mi parecer, deficiente tratamiento que la Asociación de Academias de la Lengua Española da a esta voz recientemente me he ocupado (2012c: 255-257). El mexicano Fernández de Lizardi reiterará el empleo de ancheta: "anhelaba también por entregarle su ancheta", "me franqueba el (dinero) que yo le pedía para comprar varias anchetas en el año, que daba por su medio a algunos comerciantes para que me las vendiesen en Acapulco", "tales fueron las que yo hice en Manila cuando me embarqué con mi ancheta para Acapulco" (1830-1831/2008: 437, 736, 744). La primera edición de El Periquillo Sarniento es de 1816, y los años de mi referencia bibliográfica corresponden a la tercera, en la que su editora señala variantes introducidas sobre la príncipe. 
estaba en relación comercial con casas gaditanas, por ejemplo con Javier Ignacio de Amenábar, "del comercio de Cádiz", quien lo considera "amigo", y con el mismo Miguel de Iribarren ${ }^{12}$. También por esta carta resulta evidente que el conde aludido por Orozco en la primera era Bernardo Gálvez, que había recibido el título de Conde de Gálvez, personaje de gran proyección política y militar en América, nombrado en 1784 capitán general gobernador de Cuba y ese mismo año virrey de Nueva España en sustitución de su difunto padre, Matías Gálvez. De modo que en esta carta Orozco manifiesta su amistad y la de Iribarren con el nuevo virrey, cuya madre era "la Señora Virreyna viuda" a la que iba a conducir de regreso a España ${ }^{13}$.

\section{MÁS REFERENCIAS HISTÓRICAS Y CRÍTICAS}

3.1. Los datos de contexto social que acabo de anotar ayudan a pintar el marco sociolingüístico en el que personajes como Orozco se movían en sus relaciones indianas, en las que no extrañaban usos ortográficos y lingüísticos que podían ser el seseo de un andaluz o la peculiaridad del bilingüe vasco, tampoco la construcción de adverbio ya+ $\mathrm{S}+\mathrm{V}$, por entonces muy extendida en América y vigente en Andalucía y Canarias, no siendo difícil hallar más testimonios de la época, como el proporcionado por un periódico gaditano de 1811, "con que ya usted ve que eso no está en el orden", dialectalmente en conexión con el uso registrado en Orozco ${ }^{14}$. E indudable es que el conocimiento del medio sociocultural de los hombres de negocios de Cádiz evitará calificar sin más de vulgarismo una forma de tanto arraigo en la tradición lingüística como fue recebir hasta su definitivo desplazamiento de la norma culta por la variante recibir, todavía empleada en 1778 por Miguel de Iribarren ("aier tarde receví de la almiranta de la flota los caudales de mi consignación"), en carta en la que, como Orozco, se

12 Cartas de Goya (México, 29 de julio de 1785) y de Amenábar (Cádiz, 21 de febrero de 1786): ARChV, Pleitos Civiles, Quevedo, Olvidados, caja 321-2. Un José de la Piedra figura repetidas veces en la correspondencia de Miguel de Iribarren como hombre de confianza en sus negocios de Nueva España.

13 Aparte de esa amistad, Rafael Orozco tuvo una compañía de comercio con el Conde de Gálvez (Martínez del Cerro González 2006: 407).

14 Diario Mercantil del 1 de diciembre de 1811, en texto que reproduce íntegro Sánchez Hita (2008: III, 448). 
muestra leísta; en el caso de Iribarren tanto por influencia literaria como por su origen norteño: "la cláusula testamentaria que como albacea desempeña con tanto honor, y que para cubrirle me es indispensable esta suspensión", "no deviendo dudar de mi propensión a servirle, quedo rogando a Dios le guarde muchos años"15.

3.2. El trato con los fondos documentales precave contra la tentación de zanjar la cuestión de la distinción lo/le y del leísmo en América con apresuradas y gruesas pinceladas descriptivas, pues el panorama lingüístico era de gran complejidad, como compleja era la sociedad americana en sus usos idiomáticos, así como las corrientes migratorias, sin olvidar lo que al respecto podía suponer la relación entre lengua hablada y lengua escrita. Con apoyo empírico se podrá poner en tela de juicio, si no descartar rotundamente, que fuera "caótica" la ortografía americana y que supusiera un riesgo para la unidad del idioma. El análisis de textos como los de Orozco demuestra que ni había caos en la escritura ni jamás corrió el español peligro alguno de fragmentación por este motivo. Debe tenerse en cuenta que la letra impresa estaba más uniformada que la manuscrita, esta sujeta a un mayor apego a la tradición y a la variación impuesta por la diversidad de principios escolares, por lo de aquel "cada maestrillo tiene su librillo". Y que comúnmente no hubo notables diferencias entre los usos americanos y los de la metrópoli, con la salvedad de un conservadurismo ortográfico que podía ser más acusado en el escribano ultramarino.

Se ha visto, así, que la jota de trazo elevado sobre la caja de escritura está lo mismo en los autógrafos de Orozco que en las cartas que un amanuense le copia en México y Veracruz, y desde luego esta grafía por los mismos años también era usual en la manuscritura española. Se encuentra, en efecto, en denuncia hecha el año 1808 por Antonio Alonso, cura de San Esteban, en la mexicana Guadalajara, contra un opúsculo que juzgaba subversivo (El voto de un español), así como en la respuesta oficial que se le da desde Madrid, y aún competía este dibujo de la jota con el moderno en actas del Consejo de Ministros español de 1833 a 1838, aunque más tarde todavía empleaba de forma sistemática esta letra con su trazo antiguo Carlos Antonio López, presidente de la República del Paraguay, en autógrafo de c. $1860^{16}$.

15 Escrita de Cádiz a México en julio de 1778 como apoderado del brigadier Domingo de Elizondo, albacea de un disputado legado testamentario (misma localización de la citada en la nota 1).

16 Los datos referentes a 1808 en Archivo Histórico Nacional, Consejos, 11991, expediente 1. Hay textos ministeriales de los años indicados con uso constante de la $j$ de 
3.3. Si Orozco alguna vez pone $r r$ tras consonante en honrrado (carta en n. 7), y su amanuense escribe rreales en la segunda misiva, el mismo empleo he atestiguado en textos americanos hasta mucho después, igual que el de esta doble letra a comienzo de palabra, que figuraba en el siguiente pasaje de la carta escrita el 1 de mayo de 1734 en Veracruz por Gabriel Sánchez de Mora a Blas de Madrona, residente en Cádiz: "el dicho contramaestre lleua a su cuidado un cajonzito de vúcaros y losa de China y otros juguetes y vn lienzo de unos rretratos y tres bateas" ${ }^{17}$. Por cierto que esta cita registra la $u$ con valor consonántico (lleua) y la $v$ vocálica ( $v n)$, además de un losa con $s$ por $z$ en texto sin más desliz seseoso, como ocurre con el único ejemplo de otro losa en la tercera carta de Orozco y el de balisando de la segunda.

Para no alargar el muestreo de variantes grafemáticas, me fijaré en la misiva autógrafa que en 1786 dirige a Iribarren el andaluz Pascual José Portillo, maestre de navío, a propósito de la acusación que sobre él pesaba a cuenta de la plata que había traído de Veracruz, misiva escrita con resabios arcaicos: pudiesse junto a tubiese, escriuí con $u$ consonántica, y con $v$ vocálica avn, vsar, vsado, pero también con grafías de referencia fonética meridional, quién sabe si del particularismo ceceoso gaditano (comizión, conciderar $)^{18}$.

3.4. La cacografía seseo-ceceosa tiene infinidad de testimonios en el epistolario personal, como no podía de otra manera ser cuando el fenómeno andaluz, canario y americano llevaba siglos de arraigo, aunque aquí que el texto sea autógrafo o copia no es indiferente en la identificación del hablante-escribiente, y por tanto de su naturaleza regional. Así, sabemos que era vasco José Santiago Inciarte, asociado de Iribarren en Nueva España y, sin embargo, no eran de su autoría los lapsus que en dos cartas, con solo la firma de su puño y letra, se cometen ${ }^{19}$. En la primera (Veracruz, 31 de julio

dibujo actual; otros con este signo sin puntuar; están los que alternan las dos jotas con y sin punto superpuesto, y los que tienen la antigua letra en exclusividad, con prolongación sobre la caja de escritura y sin punto: actas facsimilares en edición de García Fernández (1995: 539625). También sistemáticamente usaba esta jota tradicional bastante más tarde el mencionado político paraguayo: Biblioteca Nacional de España, Ms. 18637-61.

17 ARChV, Pleitos Civiles, Alonso Rodríguez, Olvidados, caja 738-2. Obsérvese en la anterior cita el empleo del indoamericanismo batea, que asimismo figura en la carta de Diego Barreda escrita en México el año 1783: "y encontrarnos haora con tal batea de babas, puedes hazerte cargo qué doloroso me habrá sido..." (cfr. n. 11).

18 AHPC, Fundación Luis Goytisolo, Familia Iribarren, caja 63, expediente 11. De estas cuestiones me he ocupado en estudios recientes (2012a, 2012b).

19 Ibíd., caja 63, expediente 30, las dos cartas. 
de 1776), de gran extensión y escrita por dos amanuenses, es el segundo, quien menos espacio ocupa pero como consumado pendolista, el que cae en el único desliz de conosimientos; en la segunda (Jalapa, 30 de mayo de 1777) el excelente calígrafo que la copia desliza los errores de concecuencia y subsesivo, pocos para la magnitud del corpus epistolar. Algo parecido se comprueba en carta que José Pobil, alto funcionario de la administración colonial, escribe a Miguel de Iribarren en La Paz el 17 de enero de 1806 mediante escribano de muy buena letra, con la sola falta de dispocisión, mientras ningún error de este tipo hay en la que le remite desde Lima el 23 de marzo de 1805 con amanuense de distinta letra ${ }^{20}$.

\section{4. ÚLTIMAS CONSIDERACIONES}

4.1. De todo lo expuesto se obtiene una prueba más de que en materia ortográfica no había uniformidad, aunque sí bastantes pautas comunes, ni en el español escrito en América ni en el de España, nada extraño esto cuando la variación en alguna medida se daba incluso en los mejores diccionarios de la época de referencia, segunda mitad del siglo XVIII y primeros años del XIX, también en los académicos, aunque la fluctuación en la representación grafémica de los sonidos fuera bastante mayor en los textos manuscritos que en los impresos ${ }^{21}$. Pero sin que se pueda trazar una divisoria entre la scripta americana y la metropolitana.

El acercamiento a fidedignas fuentes textuales, hablen cartas y callen barbas, ayuda al correcto enfoque diacrónico, de modo que una y otra vez se comprueba que a mayor cultura y prurito normativo más difícil resulta la ruptura de los moldes ortográficos por una pronunciación del autor dialectalmente diferenciada. Indudablemente era indistinguidor el gaditano Miguel Rodríguez de Carassa, con esta grafía firma, quien en misiva a Miguel de Iribarren, del 29 de octubre de 1781, de buena letra y ortografía por lo general más moderna que la de Orozco, pero con una suelta $u$ consonántica

$20 \quad$ Ibíd., caja 63, expediente 9.

21 En América por los años de la Independencia se observan notables diferencias, poco a poco borradas, entre los territorios con antigua presencia de la imprenta, como Nueva España, y Chile u otros dominios hasta entonces desprovistos de industria editorial, en los que al principio la letra impresa tuvo alguna dependencia de la manuscrita. 
(“suplicándole me haga el fauor..."), su pronunciación regional solo aparece en los retoques existentes sobre una $z$ y una $s$ en afizsionado 'aficionado', en un probable intento de enmendar lo que juzgaría error de su escritura ${ }^{22}$. Pero su seseo o su ceceo no era ocasional, como tampoco lo era la indistinción yeísta en el oficial gaditano de notaría que en inventario testamentario pone correctamente mantilla, monillos, pocillos, servilletas, toallas, y también dos veces bayeta, pero en otros renglones balletas y balleta con deslices gráficamente lleístas, en la segunda cacografía con su anómala $l l$ rehecha bajo la caja de escritura por una $y^{23}$.

4.2. Claro que no es solo cuestión de ortografía y de fonética lo que la documentación de la época pone de relive sobre el español hablado y escrito en los años que se encaminaban hacia la independencia americana, aunque por supuesto el conocimiento de estos aspectos culturales y lingüísticos es imprescindible si se quiere evitar la baldía reiteración de tópicos, que únicamente oscurecen la visión de la historia, de todo lo cual con más detenimiento he tratado en otra parte (2010: 119-150). Respecto de la gramática por los datos que en estas páginas se han citado, recordaré la datación vascongada y gaditana del indefinido cualesquier-cualesquiera con sustantivo en singular (v. n. 5), uso del que aún he registrado mayor frecuencia por las mismas fechas en América, donde continúa vigente (2010: 250). Asimismo están verificados aquí testimonios del esquema morfosintáctico $y a+$ sujeto pronominal $+\mathrm{V}$ a finales del siglo XVIII y principios del XIX, demostrativos de la afinidad dialectal andaluza, canaria y americana, y se ha advertido que el problema del leísmo no admite simplistas soluciones para el español americano, pero ni siquiera en su implicación

22 AHPC, Fundación Luis Goytisolo, Familia Iribarren, caja 63, expediente 19. En la vuelta de esta carta hay una nota dirigida a este personaje, en la que su apellido Carassa está escrito con eses altas. En cuanto a puntuación ortográfica, apenas una ocasional coincidencia muestra este texto con los de Orozco, y es el empleo que en única ocasión su autor hace de los dos puntos (:) como punto y seguido.

23 "Ymbentario de los muebles y efectos encontrados en casa de la difunta doña Rosa García de Huerta”, documento del año 1804, de cuatro planas: AHPC, Fundación Luis Goytisolo, Familia Iribarren, caja 53, expediente 10. En la misma relación notarial se verifica un corcha enmendado colcha, y la velarización de /f/ seguida de /u/ ("13 jundas de almoadas"), amén de los andalucismos borcelana, pocillo y treves 'trébedes', el primero recogido en México y Guatemala por la Asociación de Academias de la Lengua Española, con trebe en Guatemala, El Salvador, Paraguay, Uruguay, Argentina (2010: 280, 2092). En carta dada por el andaluz Juan José Colón en México el 26 de mayo y dirigida al comerciante gaditano don Pedro Daza y Guzmán, sus ejemplos de seseo van acompañados de un selvido 'servido' (con la localización del AHPC de esta misma nota). 
andaluza, sin tener en cuenta las posibles interferencias regionales de los autores de los respectivos textos, y también la del modelo literario.

Los textos misivos analizados dan un continuo tratamiento en tercera persona entre individuos de gran familiaridad y amistad, relación que sin duda unía a Rafael Orozco con Miguel de Iribarren, lo cual sin embargo desconcertará a alguna americanista a propósito del epistolario de Domingo F. Sarmiento, sin verdadero motivo para ello. El elemento pronominal empleado es vuestra merced, continuamente abreviado vm., excepto con mucha probabilidad en el caso de la tercera carta de Orozco, donde las siglas $S . M$. ("he logrado el gusto de hacer buenos servicios a $S . M$. .") por el contexto seguramente más son de un su merced referente a Iribarren que al monarca. De hecho, a finales del XVIII y principios del XIX su merced gozaba aún de gran predicamento en América, en algunos de cuyos dominios todavía se conserva, y que en Andalucía se mantuvo hasta muy adelantado el siglo XIX. En una representación de 1787, de ambiente entre andaluz e indiano, las muchachas al tío recién llegado de Ultramar lo saludan "sea $s u$ merced bienvenido" (Ripodas Ardanaz y Lapuista 1986: 167), y en inventario de bienes fechado en Cordoba el 15 de enero de 1790 el escribano que lo redacta continuamente se refiere con un su merced al alcalde ordinario por el estado noble de la ciudad, encargado de tutelar el acto testamentario ("está su merced pronto", "dijo su merced", "su merced mandó suspender esta diligencia", etc. $)^{24}$.

El tratamiento con vuestra merced parece ser el de más distinción y protocolo en los textos considerados, sin que la amistad quedara excluida, así en las cartas de Orozco o en el billete autógrafo que el año 1787 manda el conde de Quinta Alegre a Iribarren: "Amigo mío. Si vuestra merced va a la junta de Dn. Francisco Sierra, hágame vuestra merced el gusto de representar a su fino amigo. Quinta Alegre (rubricado)"25. También es esta forma tratamiento único en las cartas de José Santiago Inciarte, mientras que en las del funcionario virreinal José Pobil ("secretario de este Govierno Yntendencia", en La Paz), de 1805 y 1806, los cuerpos epistolares llevan $V$. 'usted': "dixe a $V$. ", "como $V$. ocupa el segundo lugar en aquel documento...", "doy a $V$. este aviso", quedando la forma compuesta relegada a la expresión formularía de despedida: "Dios guarde a $\mathrm{vm}$. así, para mandar a su afectísimo servidor que su mano besa". Únicamente en la de Pascual José Portillo, de

24 Archivo Histórico Provincial de Córdoba, PNC, escribano Antonio Mariano Barroso, 12, 14416P (1790), fs. 76-163r, partición, cuenta, inventario y testamentaría de don Pedro Justo Nieto y Torres.

25 AHPC, Fundación Luis Goytisolo, Familia Iribarren, caja 63, expediente 13. 
nivel económico y social mucho menor que el círculo de Iribarren, aplica el usted lo mismo en el texto libre que en la fórmula final: "no puedo ver a $V$. hasta la tarde", "puede $V$. conciderar lo desazonado que me tendría este particular", "de $V$. su atento seguro servidor, que su mano besa".

Con la particularidad añadida de que Portillo emplea el posesivo analítico, "quando salí ayer de casa de V. pasé a el almazén del Consulado", uso gramatical con el que más se relaciona el español americano, también ya a finales de la Colonia, con el de Canarias y Andalucía que con el resto de la Península, y que curiosamente se prodigaría en los periódicos editados en Cádiz en la segunda década del siglo XIX, así estos dos ejemplos sacados de un breve párrafo: "correspondiente al oficio de la denominación de usted", "le paso a manos de usted" 26 .

4.3. La documentación andaluza y americana, durante mucho tiempo en tantos aspectos lingüísticos indisociable, también ayuda no poco a ampliar y precisar muchos datos relativos al léxico. Por este medio documental, confirmado por la encuesta en el habla hispalense, pues en la catedral de Sevilla es donde están los candelabros de plata mexicana a los que debería referirse la lexicográfica acogida de bizarrón, verifiqué que no es este vocablo para estar incluido en el diccionario académico, ni como general ni como regional (1994: 115-117), como hasta en su última edición de 2001 continúa apareciendo ${ }^{27}$. En el epistolario del comercio gaditano que manejo se atestigua asimismo que el galicismo deshabillé fue mucho más corriente en el siglo XVIII de lo que parecen indicar sus registros de dicha centuria en el CORDE, todos tomados de fuentes literarias peninsulares ${ }^{28}$, pues en carta escrita en Jalapa el 29 de septiembre de 1776 por José Santiago Inciarte a Miguel de Iribarren se lee: "hasta la fecha de esta no hemos logrado vender

26 El Procurador General de la Nación y del Rey, № 166, 15-III-1813: Biblioteca de Temas Gaditanos. Pero son muchos más los testimonios de este posesivo preposicional que en la colección periodística gaditana se encuentran.

27 Los doce blandones fueron legados en su testamento a la catedral de Sevilla, a donde llegaron el 24 de noviembre de 1752, por su antiguo canónigo, Juan Antonio de Vizarrón y Eguiarreta, Arzobispo de México y Virrey de Nueva España, hijo de navarro y de madre gaditana de origen vasco, nacido en el Puerto de Santa María. No deja de extrañar que un vocablo de esa referencia documental, de mínima vigencia en el restringido círculo catedralicio y de historiadores del arte hispalenses, aguardara al año 1936 para su recepción académica. Sobre este personaje y su entorno familiar véase también Tellechea Idígoras (1971).

28 Consulta del 1 de febrero de 2013. 
más de dos desavillés acolchados, no obstante el empeño que hemos puesto para lograr la de todas sus partes" 29 .

Algo parecido cabe decir de ancheta, término del comercio indiano traído por la tercera carta de Orozco y que con frecuencia aparece en los textos dieciochescos referentes al tráfico mercantil entre España y los puertos americanos, lo cual por un lado explica que hacia 1800 lo empleara con su sentido primario el gaditano Juan Ignacio González del Castillo, y por otro que se difundiera con acepciones secundarias como un marinerismo de tierra adentro más por toda América, donde pervive con notable extensión diatópica y variación semántica ${ }^{30}$. Así, pues, no se han expurgado las fuentes apropiadas para testimoniar la familiaridad con que esta palabra, de escasa y variable recepción lexicográfica, se usó por quienes comerciaban en la Carrera de Indias y la extendieron por los dominios ultramarinos ${ }^{31}$.

4.4. Si en la documentación están las más esclarecedoras claves del pasado lingüístico, la conservada en Cádiz aporta abundantes y rigurosos datos referentes al comercio de España con América hasta su misma independencia. Las grandes compañías comerciales y de seguros se compusieron de gentes de la ciudad y de diferentes regiones peninsulares, con especial protagonismo del importante grupo de navarros y vascos, sin olvidar la presencia de una activa minoría extranjera. Desde Cádiz se tejieron redes clientelares y familiares por los más importantes puntos de interés económico en América, todo lo cual, y las continuas expediciones mercantiles de ida y tornaviaje, dio lugar a una extraordinaria producción textual, de tipo notarial (contractual, testamentaria, etc.) y epistolar. Por las cartas intercambiadas entre Cádiz y América es posible descubrir rasgos del español hablado al otro lado del Atlántico lo mismo por criollos que por

29 AHPC, Fundación Luis Goytisolo, Familia Iribarren, caja 63, expediente 33. Se hallan también las cacografías concecuencia y subsesivo.

30 No es exhaustiva su entrada en el diccionario de la Asociación de Academias de la Lengua Española (2010: 111), como simplemente demuestra su cotejo con el de Santamaría (1978: 66) y con los datos del mismo CORDE, no obstante su parquedad en este caso. En este corpus electrónico sobran aquí las inclusiones de ancheta diminutivo de ancho.

31 Ni el Diccionario de Autoridades ni el de Terreros recogieron esta voz, que la Academia incluiría en la edición de su diccionario de 1770 con solo el originario significado del comercio ultramarino. Las tres acepciones que sin nota diatópica, la primera es la de carácter histórico, a ancheta se daba en ediciones anteriores a la de 1992 del diccionario académico, en esta se convierten en cinco, de ellas una como americana general, otra como colombiana y venezolana, y la de 'negocio, bicoca' como americana y andaluza. El andalucismo de esta última lo suprimirá la Academia en 2001, igual que el venezolanismo de la anterior acepción. 
españoles, de estos bastantes de gran arraigo en aquellas tierras y con claras trazas de criollización lingüística. Pero también queda reflejada en estos textos la diferenciación regional del español peninsular, principalmente la andaluza y la norteña de vascongados y navarros, muchos de ellos bilingües.

De cómo se sentía en toda América la preponderancia de Cádiz en el concierto comercial de España y sus colonias dan fe las innumerables críticas que se hicieron sobre el particular en los años de las guerras emancipadoras. Pero me limitaré a traer a colación esta alusión del primer periódico mexicano independentista, a cuenta de la imaginaria discusión entre un "criollito" y "un hombre de birrete, sin duda era de Santander..., con tono de individuo de los que ha muchos años gozan de voto en el Consulado de México", quien así argumenta a su antagonista:

No pensaba, dixo entonces, desencapotando un poco el ceño, que V. se paraba en eso, porque según he oído a los teólogos de la Patria, eso tiene su más y su menos; pero, vaya, haré de V. una confianza a que me obligan mis qualidades de cónsul extraordinario y oculto, y comisionista principal de muchas casas de Cádiz ${ }^{32}$.

4.5. Teniendo en cuenta que la relación diatópica marcada en este artículo ha sido principalmente la gaditano-novohispana, no estará de más observar que el corpus novelesco de Fernández de Lizardi (1830-1831/2008) abunda en referencias a afinidades lingüísticas entre los dominios mexicano y andaluz. En el aspecto fonético, por ejemplo, el yeísmo aunado al antihiato en Rial estanquiyo de puros (120); la velarización de /f/ en juere ("pagando lo que juere", 468), y el arcaizante mantenimiento de la aspiración etimológica en jerrador ("jerrador y curador de caballos", 468), jijo ("ladrón, jijo de un dimoño", 583), y en julló, aquí junto al yeísmo ("se aburrió y se julló", 507). En lo gramatical, el adverbio contimás (394) y la locución adverbial a seguida: "y a seguida se lo propones" (620), "a seguida de esto... le dije a Roque..." (635), "a seguida requerí y amenacé a todos" (682); la preposición de con valor partitivo: "una poca de gramática" (225), "tres mil y pico de pesos" (742), "una poquilla de labia" (798); la interjección ojalá y: "ojalá y no fuera su primo" (263), "ojala y yo hubiera sabido quién era" (634); numerosas muestras de la construcción ya + Pron. $+\mathrm{V}$, entre ellas: ya yo le ayudaba (516), ya yo soy cadáver (560), ya tú sabes (208), ya él estaba (378), ya usted verá

32 El Despertador Americano. Correo político económico de Guadalaxara, No 3, 29 de diciembre de 1810, pp. 19-20: en la edición El Despertador Americano: primer periódico insurgente, facsimile y proceso (México, INAH, 1964). 
(445). En el léxico, almofrez $(848,856)$, la variación genérica de banco en banca ("me recosté en una banca", 181), borcelana $(334,504)$, frangollar (675), maquear (827), pocillo $(258,428,597)$, pozuelo (259), etcétera ${ }^{33}$.

\section{REFERENCIAS BIBLIOGRÁFICAS}

Asociación de Academias de la Lengua Española. 2010. Diccionario de americanismos. Lima: Santillana Ediciones Generales.

Fernández de Lizardi, José Joaquín. 1830-1831/2008. El Periquillo Sarniento. Carmen Ruiz Barrionuevo (ed.). Madrid: Ediciones Cátedra.

Frago, Juan Antonio. 1994. Andaluz y español de América. Historia de un parentesco lingüístico. Sevilla: Junta de Andalucía. Gredos. 1999. Historia del español de América. Textos y contextos. Madrid: Editorial 2010. El español de América en la Independencia. Santiago de Chile: Taurus.

2012a. Lecciones lingüisticas en versos mexicanos de la Independencia. Boletín de la Real Academia Española 92/305: 59-84.

2012b. Razones de las reformas ortográficas en la América independiente y causas de su fracaso. Boletín de Filología de la Universidad de Chile (en prensa).

2012c. Filología y lexicografía. Notas americanas. En Dolores Corbella et al. (eds.). Lexicografia hispánica del siglo XXI: Nuevos proyectos y perspectivas. Homenaje al Profesor Cristóbal Corrales Zumbado, pp. 251-263. Madrid: Arco Libros.

García Fernández, Javier (ed.). 1995. Actas del Consejo de Ministros. Isabel II (1833-1839). Madrid: Ministerio de la Presidencia.

Lynch, John. 2009. San Martín. Soldado argentino, héroe americano. Barcelona: Crítica.

Martínez del Cerro GonzÁlez, Victoria E. 2006. Una comunidad de comerciantes: navarros y vascos en Cádiz (segunda mitad del siglo XVIII). Sevilla: Consejo Económico y Social de Andalucía.

O’Scanlan, Timoteo. 1831/1974. Diccionario marítimo español. Madrid: Museo Naval.

Ripodas Ardanaz, Daisy e Inmaculada Lapuista. 1986. El indiano en el teatro menor español del setecientos. Madrid: Biblioteca de Autores Españoles.

SÁnchez Hita, Beatriz. 2008. Cuánto cuesta la opinión pública: precios, densidad y periodicidad de la prensa gaditana (1808-1814). En Marieta Cantos Casenave et al. (eds.). La guerra de la pluma. Estudios sobre la prensa de Cádiz en el tiempo de las Cortes (1810-1814), pp. 337-454. Cádiz: Universidad de Cádiz,

Santamaría, Francisco J. 1978. Diccionario de mejicanismos. México: Editorial Porrúa.

Tellechea Idígoras, José Ignacio. 1971. Los Vizarrón. Una estirpe vasco-navarra injertada en Andalucía y México. Revista de Indias 123-124: 329-349.

33 La edición príncipe es de 1816 (cfr. n. 11). Los datos arriba aducidos de El Periquillo Sarniento no suponen sino un corto espigueo de los que esta obra contiene para la caracterización del español mexicano de la época, con notas útiles para su comparación con la variedad meridional del de España. Y, en relación con lo apuntado anteriormente sobre el leísmo en textos andaluces (v. n. 7), el de Fernández de Lizardi en buen número registra casos de este fenómeno, y no pocos de laísmo. 